\title{
Recovery of Nitric Acid from Effluents Containing Free Nitric Acid by Solvent Extraction
}

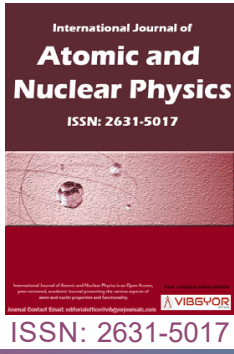

\section{Mandal}

Alkali Material \& Metal Division, Bhabha Atomic Research Centre, India

\begin{abstract}
Chemical and metallurgical industries produce as well as discharge a huge quantity of effluents containing free nitric acid along with different metal nitrates to the environment. Disposal of such effluents with high nitrate ion concentration is a serious and global problem. Recovery and reuse of free nitric acid present in such effluents may solve this problem to an extent. Free nitric acid from aqueous solution can be recovered by solvent extraction. In previous studies, such attempts were made and Tri-Butyl Phosphate (TBP) was used as solvent for this purpose, but TBP has some limitations. In the present study performance of different solvents viz. Methyl isobutyl ketone (MIBK), Di-2-ethylhexyl phosphoric acid (D2EHPA) and tetra-octyldi-glycol amide (TODGA) were investigated for the recovery of nitric acid from aqueous nitricacid solution in presence of various metal ions, which may be considered as simulated effluents and the same has been compared with that of TBP. From the experimental results it was found that TODGA is the best solvent among these four solvents viz., TBP, D2EHPA, MIBK and TODGA for the extraction of nitric acid from effluents containing free nitric acid. Experimental details and results are discussed in this paper.
\end{abstract}

\section{Keywords}

Nitrate removal, Nitrate ion, Nitric acid recovery, Solvent extraction, Methyl-iso-butyl ketone, Di-2-ethyl hexyl phosphoric acid, Tetra-octyl di-glycol amide

\section{Introduction}

Nitrate contamination in drinking water is a serious and global problem. Nitrate has many harmful effects as shown in Table 1 [1-8]. Nitrate contamination of drinking water causes methemoglobinemia; a disease, which causes the reduction in oxygen-bearing capacity of blood. As a result, when a person is suffering from methemoglobinemia may even die. Nitrate contamination in foods and drinking water; beyond permissible limit causes cancer.
World Health Organization (WHO) has set the limit of nitrate ion concentration in drinking water as 44 $\mathrm{mg} / \mathrm{l}(\mathrm{ppm})$ whereas; the nitrate ion concentration in the nitrate bearing effluents is of the order of 30-200 g/l. Regulatory boards in different names in different countries; set the maximum permissible limit for discharge of nitrate ion in effluent which is the same order that set by WHO. In the United States the discharge limit of nitrate is $44 \mathrm{mg} / \mathrm{l}$, in Europe this limit is $50 \mathrm{mg} / \mathrm{l}$ whereas, in India it is $44.3 \mathrm{mg} / \mathrm{l}$ for the inland surface water discharge

*Corresponding author: D Mandal, Alkali Material \& Metal Division, Bhabha Atomic Research Centre, Trombay, Mumbai-400085, India

Accepted: November 07, 2020; Published: November 09, 2020

Copyright: (C) 2020 Mandal D. This is an open-access article distributed under the terms of the Creative Commons Attribution License, which permits unrestricted use, distribution, and reproduction in any medium, provided the original author and source are credited.

Mandal. Int J At Nucl Phys 2020, 5:023

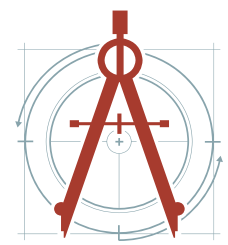


Table 1: Bad effects of nitrates in human body and on environment.

\begin{tabular}{|l|l|}
\hline Effects & Brief description \\
\hline Methemoglobinemia & $\begin{array}{l}\text { Nitrate contamination in drinking water causes methemoglobinemia; a disease in which } \\
\text { oxygen-bearing capacity of blood is reduced. Haemoglobin in blood carries oxygen from } \\
\text { the lungs to all other tissues but methaemoglobin is incapable of carrying oxygen. Even, } \\
\text { formation of enough methaemoglobin (about } 80 \% \text { of total haemoglobin) causes death. } \\
\text { Mainly, new born babies and nursing mothers are prone to suffer by methemoglobinemia. }\end{array}$ \\
\hline $\begin{array}{l}\text { Carcinogenic } \\
{[1,2]}\end{array}$ & $\begin{array}{l}\text { Nitrates may cause carcinogenic effect in human body. Under abnormal circumstances } \\
\text { nitrate is reduced to nitrite in the stomach and from N-nitrosamine, a postulated cause of } \\
\text { stomach cancer. }\end{array}$ \\
\hline Miscellaneous effects. & $\begin{array}{l}\text { Nitrate contamination in drinking water also has a negative effect on the human's health, } \\
\text { which could result in many other diseases, such as birth defects, spontaneous abortion, } \\
\text { [4-7] }\end{array}$ \\
\hline $\begin{array}{l}\text { increased infant mortality, diarrhoea, abdominal pain, vomiting, diabetes, hypertension, } \\
\text { respiratory tract infections and changes in the immune system. }\end{array}$ \\
\hline [8] & $\begin{array}{l}\text { High nitrate concentration in closed water body promotes algal blooms and water pollution } \\
\text { with eutrophication. Nitrate concentrations in surface waters are usually below } 5 \text { ppm, but } \\
\text { higher concentrations are often observed in groundwater in different places around the } \\
\text { world. Moreover, nitrate levels in drinking water in all developed countries are increasing } \\
\text { day by day, which is a global and serious issue. }\end{array}$ \\
\hline
\end{tabular}

and $88.6 \mathrm{mg} / \mathrm{l}$ for the marine coastal discharge [9].

Nitrate containing effluents are the major source of nitrate contamination in drinking water $[1,2]$. Such effluents are produced from chemical as well as metallurgical industries, which use nitric acid. Generally, nitric acid is used as a dissolving agent in these industries and normally which is used in excess than the stoichiometric requirement. As a result, effluents contain various metallic nitrates as well free nitric acid. Since all nitrates are soluble in water, it is not possible to separate nitrates by precipitation. It is not possible to remove nitrates by conventional effluent treatment processes viz. coagulation, flocculation, lime softening or surface adsorption, precipitation, adsorption and filtration. Specialized processes viz. thermal decomposition, biological and chemical process, etc. are need to be used for removing nitrates from drinking water and effluents.

Solid nitrates are decomposed at higher temperature and in thermal denitration; nitrates present in effluent first dried up by spraying in a fluidized bed reactor and thermally decomposed and generate pollutant gases, viz. NOx [10-12]. Normally, these wastes contain free nitric acid of high concentration. The same cannot be recycled due to building up of radio-activity. In biological denitration process, nitrates are decomposed by using bacteria and microbes. Various denitration processes viz., biological, chemical, thermal and other various miscellaneous processes, developed for the removal of nitrate ions from water and effluents along with their advantages and disadvantages are discussed in details somewhere else [9]. A comprehensive review of nitrate removal techniques has been published by Kapoor and Viraghaven [13].

In recent years; Various researchers attempted to separate metal ions or recover nitric acid from acidic effluent containing free nitric acid [12,1418]. Sato et al. [19] developed an adsorbent with a phosphonic acid di-butyl ester-type group by chloro-methylating styrene and di-vinyl-benzene copolymer of different di-vinyl-benzene content following phosphorylation for the preferential adsorption of nitric acid from effluent in presence of $\mathrm{HCl}, \mathrm{NaCl}$, copper sulphate and nickel sulphate. They observed that nitric acid may be adsorbed up to a concentration of $2 \mathrm{M}$. Kulkarni [20] studied an emulsified liquid membrane process using tri-n-octyl-phosphine oxide and sodium carbonate for the preferential separation of uranium (VI) ions from aqueous nitric acid solution in presence of $\mathrm{Fe}(+\mathrm{III})$, $\mathrm{Ca}(+\mathrm{II})$, and $\mathrm{Mg}(+\mathrm{II})$ ions. Stankovic et al. [21] used calix-4-arene amide derivatives to separate silver ion from nitric acid solution. Alcock et al. [22] measured the mutual solubility of TBP and water and in the presence of nitric acid and of various inert diluents for the TBP. They had also studied the distribution of nitric acid in TBP and concluded that in the process the most important compound formed is 
$\mathrm{HNO}_{3}$.TBP and this may be partly hydrated. Mishra et al. [23] also studied the solubility of TBP in nitric acid of various concentrations (0-14 $\mathrm{M})$ in the temperature range of 25 to $60{ }^{\circ} \mathrm{C}$. They have calculated the concentrations of TBP dissolved in aqueous phase, both free and bound to the acid due to the formation of TBP complexes with nitric acid. They have also studied the effect of temperature and the presence of heavy metal ions such as zirconium and ruthenium on the solubility of TBP in aqueous phase. Shin et al. [15] developed a process to recover nitric acid from the waste stream containing acetic acid hydrofluoric acid, and silicon generated from silicon wafer industry using solvent extraction with Tri-Butyl Phosphate (TBP) [24]. Lan et al. [25] used diffusion dialysis with homogenous anion exchange membrane for the recycling of spent aqueous nitric acid solution containing $\mathrm{Li}^{+}, \mathrm{Na}^{+}, \mathrm{K}^{+}, \mathrm{Mg}^{2+}$ and $\mathrm{Ca}^{2+}$ ions. Biswas et al. [14] evaluated the use of di-nonyl phenyl phosphoric acid (DNPPA) and its synergistic mixtures with neutral oxo-donors for extraction and recovery of uranium from aqueous nitric acid solution.

Zhang and Muhammed [26] studied the extraction of nitric acid from concentrated phosphoric acid solutions using methyl isobutyl ketone (MIBK) dissolved in aromatic diluent. They found that nitric acid can be effectively removed by MIBK from the solutions containing $50-75 \% \mathrm{H}_{3} \mathrm{PO}_{4}$. They also found that with increasing the concentration of either $\mathrm{H}_{3} \mathrm{PO}_{4}$ or MIBK, the distribution coefficient of $\mathrm{HNO}_{3}$, increases but the separation factor for $\mathrm{HNO}_{3}$, against $\mathrm{H}_{3} \mathrm{PO}_{4}$, decreases and they concluded that, it is possible to achieve a complete removal of $\mathrm{HNO}_{3}$, in a few of stages and the co-extraction of $\mathrm{H}_{3} \mathrm{PO}_{4}$ can be limited to less than $1 \%$. Mc Lachlan et al. [27] studied extraction of nitric acid into the single extractant systems (TODGA and TBP) and derived equilibrium constants. They found some deviations in equilibrium constant values at high nitric acid concentration due to formation of mixed complexes.

Tri-Butyl Phosphate (TBP) is generally used for the purification of crude uranium, thorium and plutonium from nitric acid medium by solvent extraction [12]. It is known that TBP can extract nitric acid from aqueous solution $[1,17]$. Hesford and Mckay [28] reported that TBP extracts acids in the order $\mathrm{HF} \approx \mathrm{HClO}_{4}>\mathrm{HNO}_{3}>\mathrm{H}_{3} \mathrm{PO}_{4}>\mathrm{HCl}>\mathrm{H}_{2} \mathrm{SO}_{4}$ in a pure system.
Nitric acid completely dissociates in diluted aqueous solution as shown in Reaction (1).

$$
\mathrm{HNO}_{3 \mathrm{aq}} \rightarrow \mathrm{H}^{+}{ }_{\text {aq. }}+\mathrm{NO}_{3}^{-} \text {aq }
$$

TBP extract nitrate acid from aqueous solution as shown in Reaction (2).

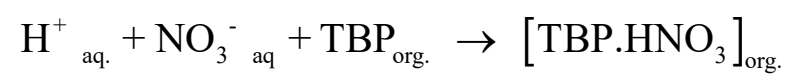

Muhsan et al. [29] have studied the extraction of nitric acid from aqueous solution, in presence of presence of metal ions viz. $\mathrm{Na}^{+}, \mathrm{Ca}^{2+}$ and $\mathrm{Mg}^{2+}$ and they have also compared with that of the extraction and stripping behaviour in absence of metal nitrates. They concluded that the nitric acid removal from effluent stream is a sustainable process to control the nitrate discharge and limiting the consumption by its possible recovery and recycling. The extraction of nitric acid may be enhanced by the addition of $\mathrm{H}_{3} \mathrm{PO}_{4}$ and nitrate salts in the aqueous phase and the extraction of nitric acid is reduced by increasing the concentration of fluoride ions (e.g., $\mathrm{HF}, \mathrm{MgF}_{2}$ etc.) in the feed solution [30].

In all the previous studies the extraction of nitric acid from aqueous solution using different extractants other than TBP, viz. methyl isobutyl ketone, di-2-ethylhexyl phosphoric acid, and tetraoctyl di-glycol amide were not investigated. The purpose of the present study is to find a suitable solvent which can extract nitric acid from effluent containing free nitric acid in presence of various metal nitrates. This will solve nitrate contamination in the environment and nitrate concentration in the effluent can be maintained below permissible limit as well as nitric acid can be recovered and reuse. Experiments were carried out with simulated effluent using different solvents viz., Methyl-Iso-Butyl-Ketone (MIBK), Di 2-Ethyl Hexyl Phosphoric Acid (D2EHPA) and N, N, N', N'-Tetraoctyl-3-Oxapentanediamide (TODGA) at different nitric acid concentrations (1-4 M) for the recovery of nitric acid from aqueous solution. The experimental with these solvents have been compared with that with TBP. The objective of the study is to find a better solvent for the extraction of nitric acid from effluents containing nitric acid which will solve the disposal of nitrate waste. The experimental details and results are discussed in this paper.

\section{Distribution Coefficient}

Distribution coefficient $(D)$ is defined as the ratio of the concentration of nitric acid in organic phase 
and the concentration of nitric acid in aqueous phase, as shown in Eq. (3).

$$
D=\frac{\text { Concentration of nitric acid in organic phase }}{\text { Concentration of nitric acid in aqueous phase }}
$$

In Eq. (3), the organic phase indicates the solvent diluted with a diluent. Dodecane was used as diluent in all the experiments.

\section{Stripping of Nitric Acid}

The nitric acid extracted by solvent phase may be easily recovered by a process called stripping, which is just opposite of extraction. Acidified distilled water may be used to recover the extracted nitric acid from the organic phase. Almost quantitative stripping of nitric acid is possible in multi-stage counter-current operations by using suitable volume ratio of organic to aqueous phases.

\section{Materials \& Methods}

\section{Materials}

In the present study experiments were conducted to study the recovery of nitric acid $\left(\mathrm{HNO}_{3}\right)$ from aqueous nitric acid solution of different initial concentrations (1-4 M) and containing metal ions viz. $\mathrm{Na}^{+}(10 \mathrm{~g} / \mathrm{l})$ and $\mathrm{Mg}^{2+}(10 \mathrm{~g} / \mathrm{l})$; By using four different solvents viz., Methyl Iso-Butyl Ketone (MIBK), Di-(2-EthylHexyl) Phosphoric Acid (D2EHPA), Tributyl Phosphate (TBP) and Tetra-Octyl-Di-Glycol Amide (TODGA). 70\% AR grade nitric acid (make: Merck), AR grade sodium nitrate (make: Merck), $A R$ grade magnesium nitrate (make: Merck) and distilled water were used to prepare feed solution. AR grades; MIBK (make: Sigma Aldrich), D2EHPA (make: Sigma Aldrich), TBP (make: Marc) and TODGA (make: Sigma Aldrich) were used. Figure 1 shows the geometry of these solvents. Anhydrous dodecane (> 99\%, make: Merck) was used as diluent of these solvents.

\section{Methods}

In all the experiments were carried out with solvents; Diluted with dodecane (10-80\% by volume). Initially, aqueous nitric acid solutions were prepared using $70 \%$ AR grade nitric acid and distilled water and concentrations were varied from 1-4 M and each set of experiments. Sodium nitrate and magnesium nitrate was dissolved in the aqueous nitric acid solution and concentration of $\mathrm{Na}^{+}(10$ $\mathrm{g} / \mathrm{l})$ and $\mathrm{Mg}^{2+}(10 \mathrm{~g} / \mathrm{l})$ maintained in each samples. Solvent extractions experiments were repeated at least three times. The concentration of nitric acid in aqueous as well as in organic phases; in all the
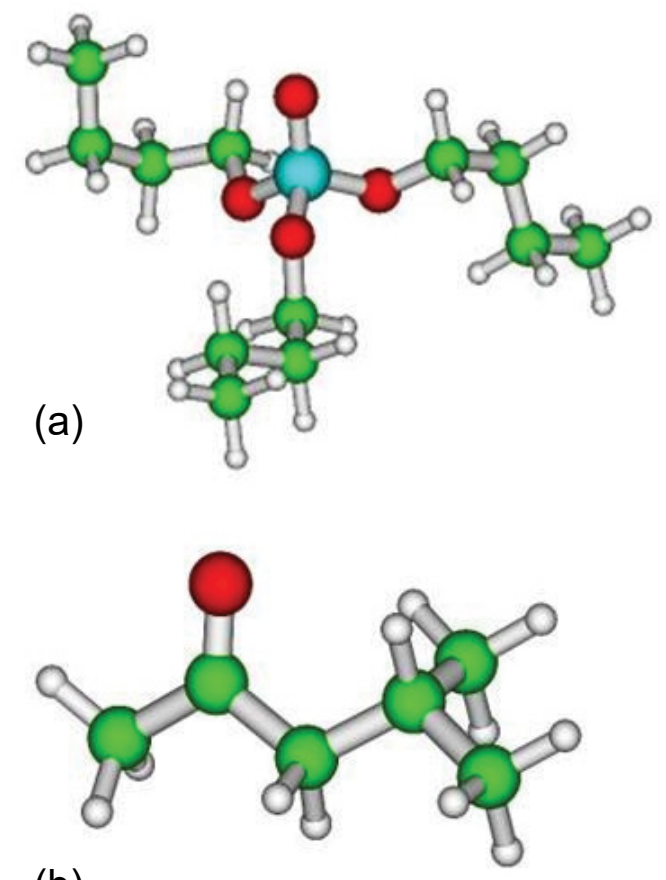

(b)

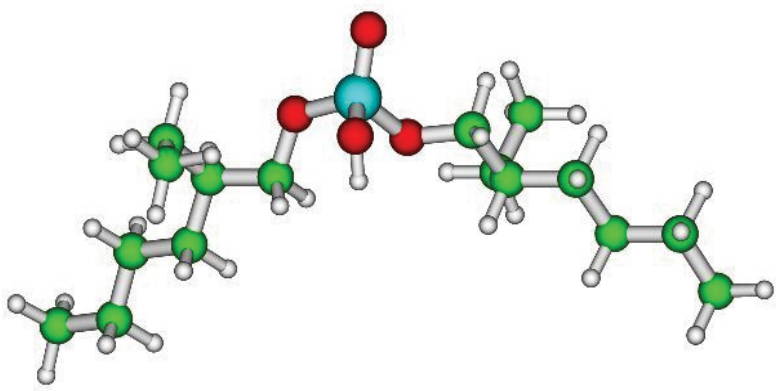

(c)

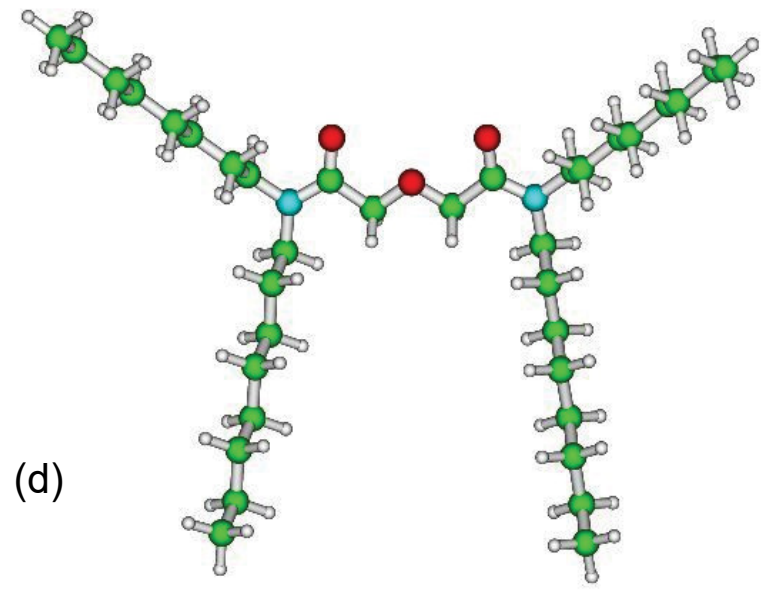

Figure 1: Molecular structures of different solvents used in the present study: a) TBP; b) MIBK; c) D2EPHA ; d) TODGA (in all the above figures, green colour indicates carbon atom, off white indicate hydrogen atom, red colour indicate oxygen atom and blue colour indicate phosphorous atom).

experiments were measured by titration using standard $0.1 \mathrm{M} \mathrm{NaOH}$ solution. The reproducibility 
of the results was within $1 \%$. Equilibrium concentration of the nitric acid in raffinate after extraction was determined by titration with $0.1 \mathrm{M} \mathrm{NaOH}$ solution.

In the present set of experiments, the stripping of nitric acid from the extract was studied, except few instances viz., extraction with TODGA. It was found the stripping of nitric acid from the extract is possible by using acidified distilled water.

\section{Results and Discussions}

\section{Extraction with TBP}

Reaction (1) and (2) shows the mechanism of nitric acid extraction using TBM. Reaction (4) shows the stripping of nitric acid to reuse from the extract, which is the reverse of the extraction reaction.

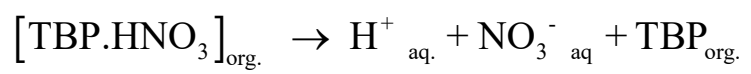

Figure 2 shows the variations of the distribution coefficient of nitric acid with mole-fraction of TBP with initial concentrations of nitric acid in the range of 1-4 M. It was observed that distribution coefficient (D) increases with increase of mole fraction of solvent in organic phase. This due to the increase in mole fraction of TBP in dodecane the uptake ca- pacity of nitric acid in organic phase increases, as a result, the value of $D$ increases. Moreover, it was also observed that with the increase in nitric acid concentration in aqueous solution, the distribution coefficient decreases with the mole-fraction of solvent in diluent. According to the definition of distribution coefficient (D) as shown in Eq. (3), as the concentration of nitric acid in organic phase increases or the same in aqueous phase decreases, the value of $D$ increases. Similarly, for any mole fraction of TBP in dodecane, with increase in nitric acid concentration in aqueous phase, the denominator in Eq. (1) i.e., the concentration of nitric acid in aqueous phase increases, as a result the value of D decreases, as shown in Figure 2.

\section{Extraction with D2EHPA}

The extraction mechanism of nitric acid from aqueous solution using D2EHPA is shown in Reaction (5).

$$
\mathrm{H}^{+}{ }_{\text {aq. }}+\mathrm{NO}_{3}^{-} \text {aq }+ \text { D2EHPA org. } \rightarrow\left[\text { D2EHPA. } \mathrm{HNO}_{3}\right]_{\text {org. }}
$$

Stripping of nitric acid from the extract using aqueous acidic solution will be the reverse of the extraction reaction as shown in Reaction (6).

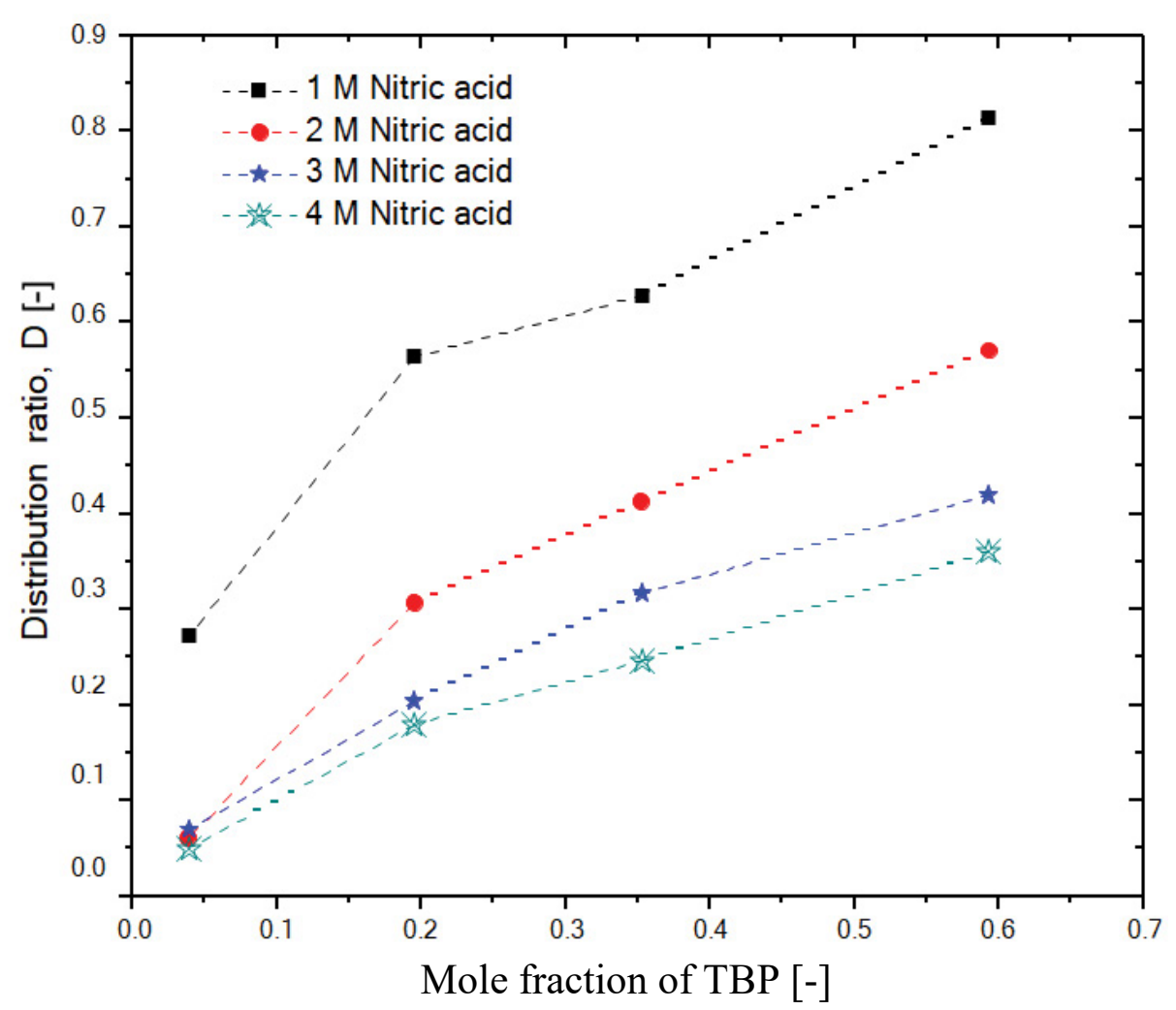

Figure 2: Variations of distribution ratio of nitric acid with mole-fraction of TBP, for different initial concentrations of nitric acid in aqueous solution (1-4 M). 


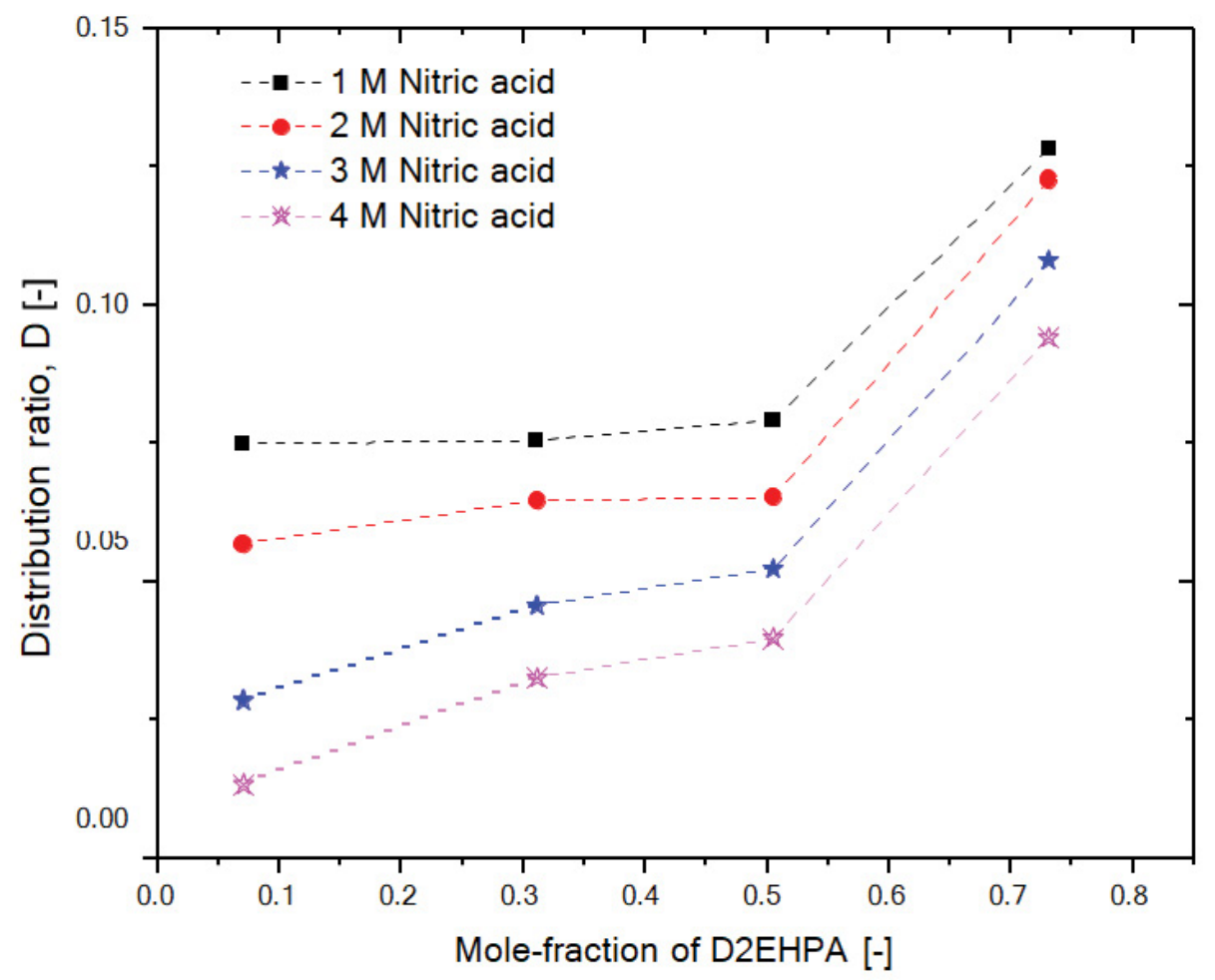

Figure 3: Variations of distribution ratio of nitric acid with mole-fraction of D2EHPA with the mole fraction of D2EHPA, for different initial concentrations of nitric acid in aqueous solution (1-4 M).

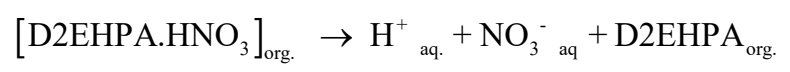

The variations of the distribution coefficient of nitric acid with the mole-fraction of D2EHPA with initial concentrations of nitric acid in the aqueous phase in the range of 1-4 $\mathrm{M}$ are shown in Figure 3. It was found that, the distribution coefficient (D) increases with increase in mole fraction of D2EHPA in organic phase i.e., mole fraction of D2EHPA in dodecane-D2EHPA solution. The increase of the value of $D$ with increase in mole fraction of D2EH$P A$ in organic phase is that, due to the increase in mole fraction of D2EHPA in dodecane; the uptake capacity of nitric acid in organic phase increases. This observation is quite similar to that in the case of TBP, as shown in Figure 2. Moreover, it was also observed that with the increase in nitric acid concentration in aqueous solution; the distribution coefficient decreases with the mole fraction of D2EHPA in dodecane.

For a particular value of mole fraction of D2EHPA in dodecane, the uptake capacity of nitric acid in the organic phase is fixed, so with increase in nitric acid concentration in aqueous phase, the denominator in Eq. (1) increases, as a result the value of $D$ decreases, as shown in Figure 3.

\section{Extraction with MIBK}

MIBK form complex during the extraction of nitric acid from aqueous solution as shown in Reaction (7).

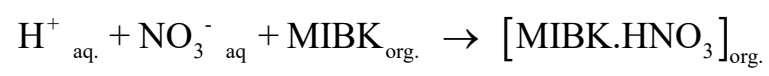

Stripping of nitric acid from the MIBK-extract using aqueous acidic solution will be the reverse of the extraction reaction as shown in Reaction (8).

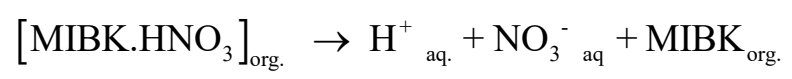

Figure 4 shows the variations of the distribution coefficient of nitric acid with the mole-fraction of MIBK with initial concentrations of nitric acid in the aqueous phase in the range of 1-4 M. It was observed that distribution coefficient (D) increases with increase of mole fraction of MIBK in organic phase i.e. solution of MIBK in dodecane, similarly in case of TBO and D2EHPA solution in dodecane as shown in Figure 2 and Figure 3. This also due to the increase in mole fraction of MIBK in dodecane the uptake capacity of nitric acid in organic phase increases, as a result, the value of $D$ increases. Moreover, it was also observed that with increase in nitric acid concentration in aqueous solution the distribution coefficient decreases for a constant 


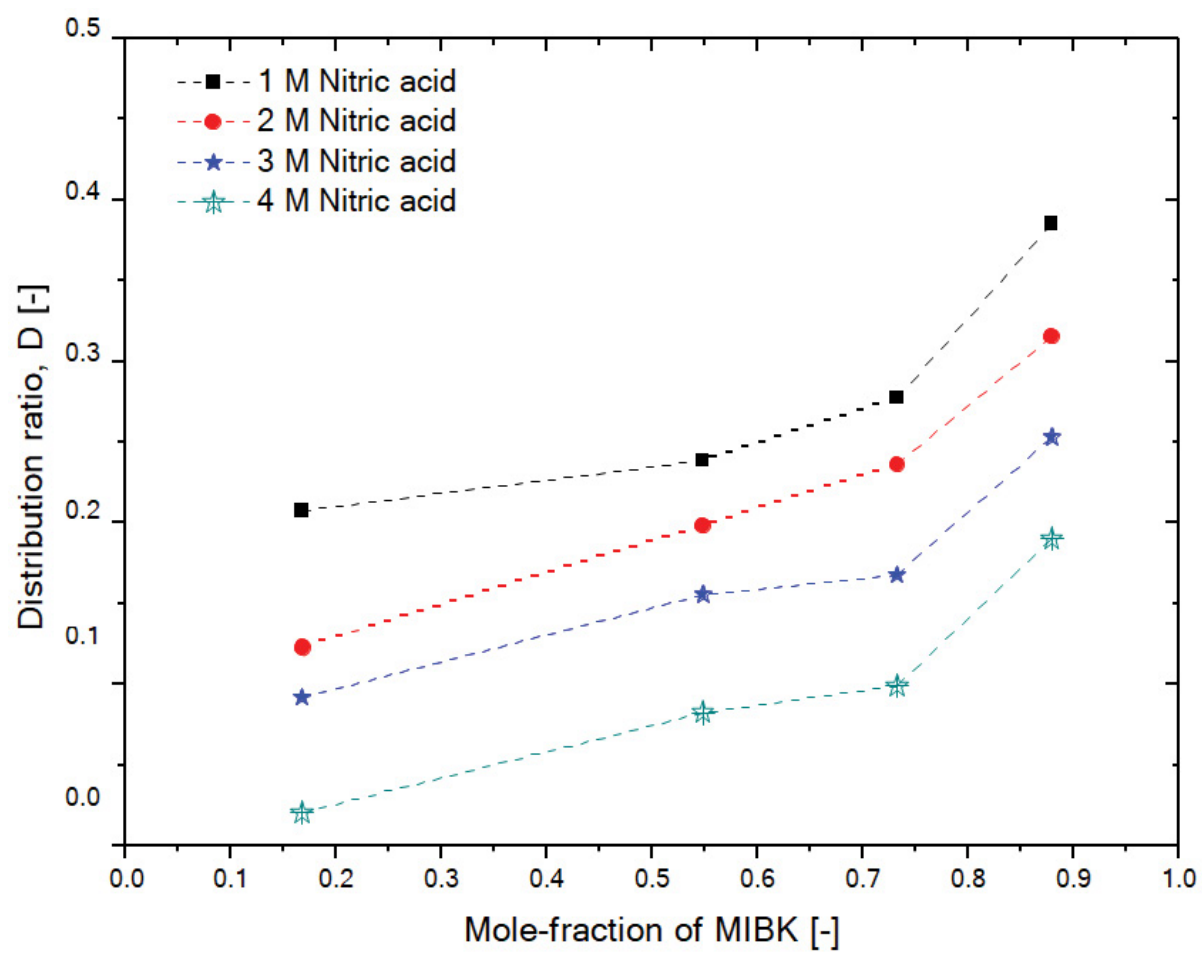

Figure 4: Variations of distribution ratio of nitric acid with mole-fraction of MIBK for different initial nitric acid $(1-4 \mathrm{M})$ in aqueous solution.

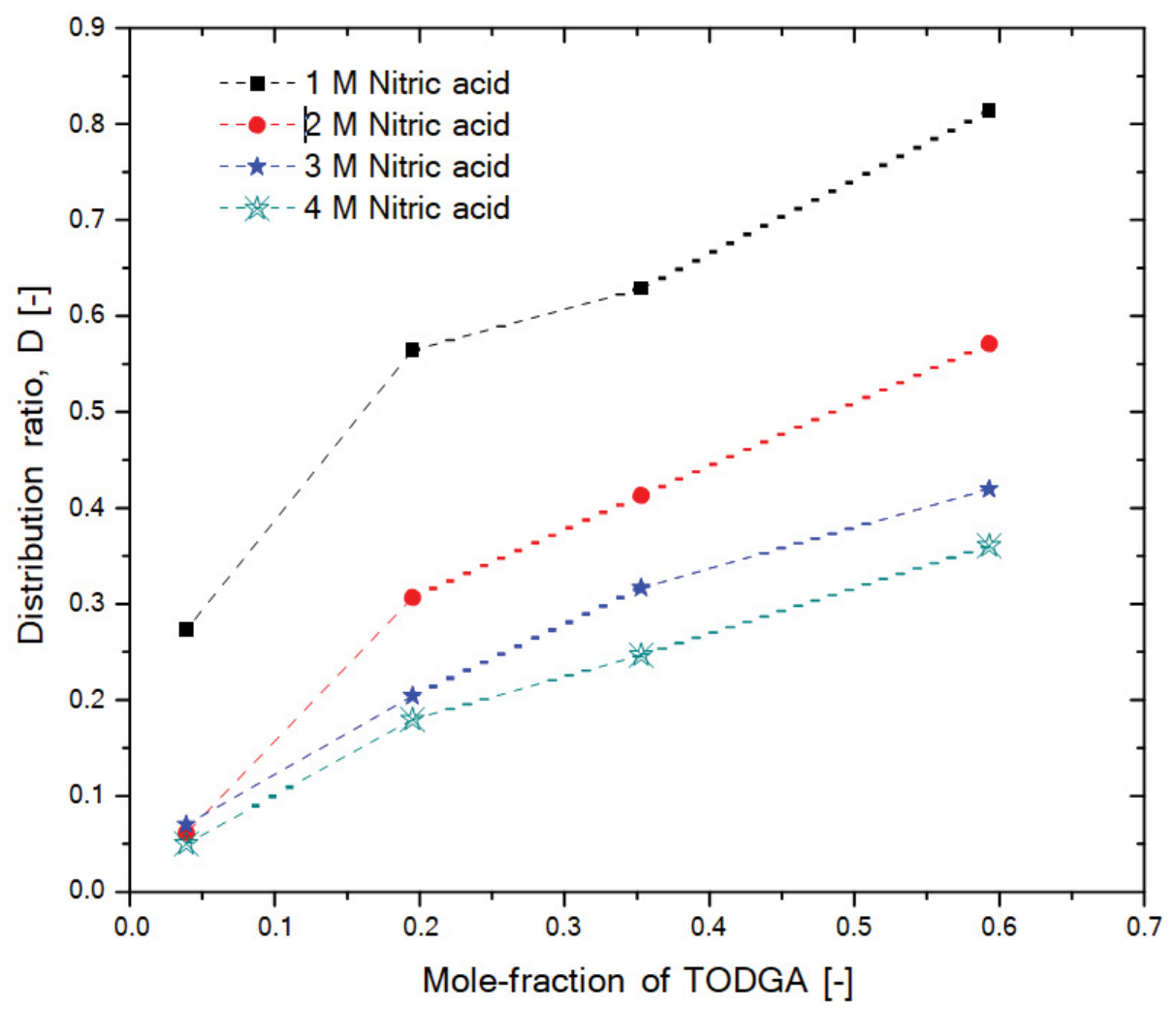

Figure 5: Variations of distribution ratio of nitric acid with mole-fraction of TODGA in dodecane for different initial concentrations of nitric acid in aqueous solution (1-4 M).

mole fraction of MIBK in dodecane. At a particular mole fraction of MIBK in dodecane, the maximum uptake capacity of nitric acid in the organic phase is fixed, so with increase in nitric acid concentra- 
tion in aqueous phase, the denominator in Eq. (1) increases as a result the value of $D$ decreases, as shown in Figure 4.

\section{Extraction with TODGA}

TODGA extract nitric acid from aqueous solution by forming complex molecule as shown in Reaction (9).

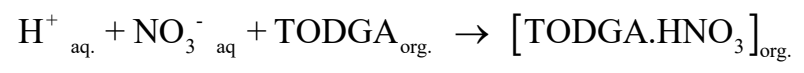

Similarly, the stripping of nitric acid from the TODGA-extract using aqueous acidic solution will be the reverse of the extraction reaction as shown in Reaction (10).

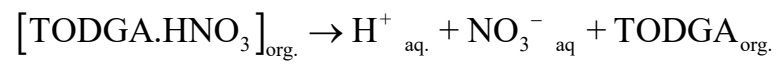

Experimental results with TODGA are shown in Figure 5. It was observed that distribution coefficient (D) increases with increase of mole fraction of TODGA in organic phase. This also due to same reasons as discussed earlier i.e., with increase in mole fraction of TODGA in organic phase the uptake of nitric acid from aqueous solution to organic phase increases, as a result, the value of $D$ increases. It was also found that for any particular value of mole fraction of TODGA in organic phase, the value of $D$ decreases with increase in molarity of nitric acid. This is due to the limitation of uptake capacity of TODGA for nitric acid from aqueous solution.

\section{Comparison of different solvents}

The change in distribution coefficient of nitric acid with mole-fraction of different solvents viz., TBP, D2EHPA, MIBK, and TODGA are shown in Figure 6 shows. Nitric acid concentration of the aqueous phase in these sets of experiments was $1 \mathrm{M}$. It was observed that, the distribution coefficient of nitric acid is the highest in case of TODGA among all these four solvents as shown in Figure 6. Thus, the extractability of the nitric acid in TODGA is higher than TBP, extractability of nitric acid in TBP is higher than that in MIBK and same in MIBK is higher than that in D2EHPA. From analysis of the COSMO-RS generated data, it was noted that TODGA is better solvent than the TBP. In fact, due to the geometry of TODGA molecule as shown in Figure 1, it easily dissolves in hydrocarbon diluent and it is behaving as a good extractant of nitric acid compared to other ligands and nitric acid is easily extracted from aqueous solution. It is believed that a fraction of ligand is dissolve in aqueous solution, which form complex molecule with nitric acid, then the com-

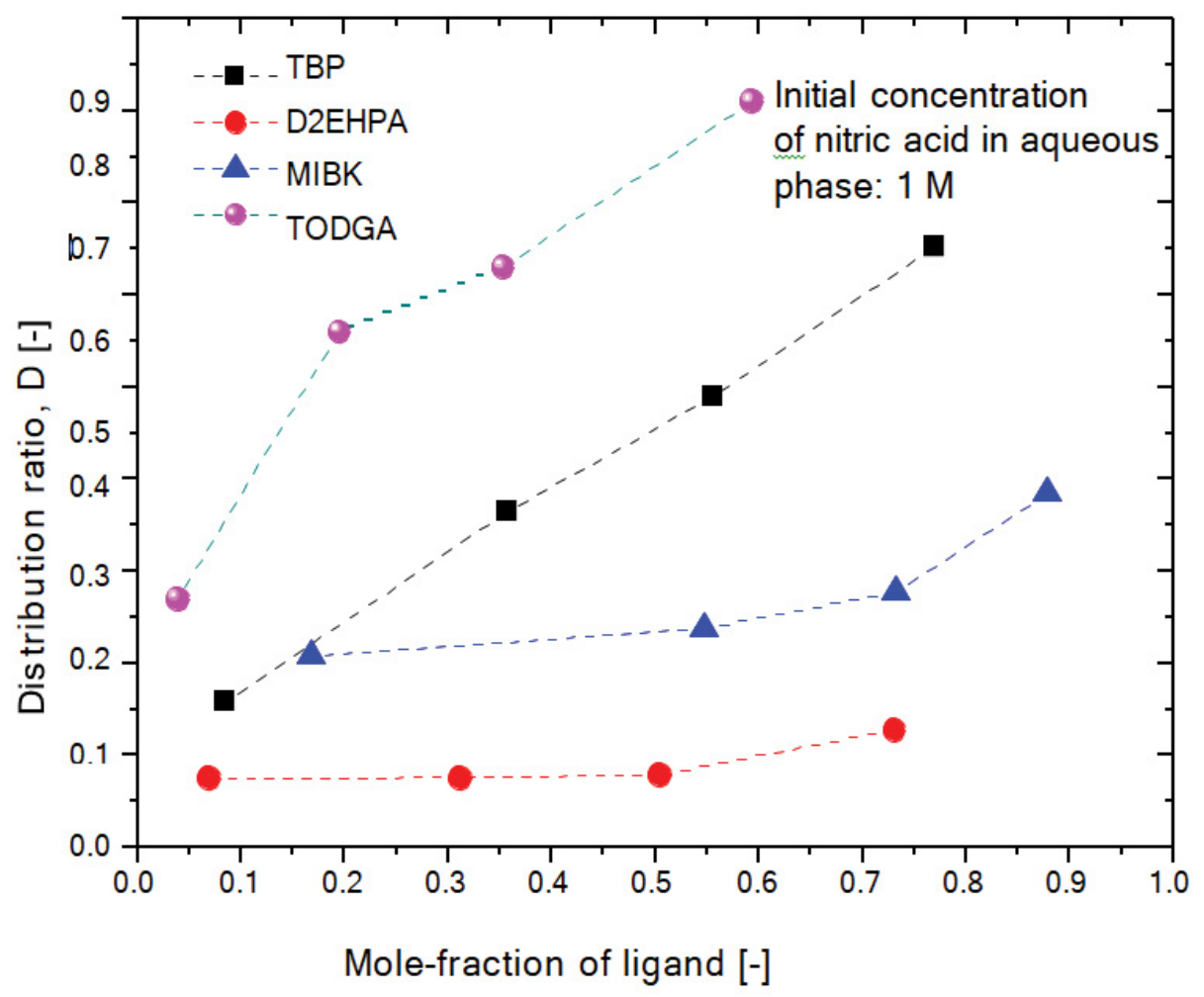

Figure 6: Variations of distribution ratio of nitric acid with mole-fraction of different ligands for initial concentrations of nitric acid of $1 \mathrm{M}$. 
plex molecule come back to the organic phase and the same process is continued, till the equilibrium state reached.

After the experiments of extraction of nitric acid from aqueous solution with four different solvents discussed above, experiments were also carried out on stripping to find the suitability of reuse of solvent and recovery of nitric acid. Distilled water, with nitric acid $(0.001 \mathrm{M})$ was used as a stripping agent in all the cases. It was found that, and they found that nitric acid was stripped from the loaded organic phase containing nitric acid and almost quantitative stripping of nitric acid was possible in case of all the four solvents.

\section{Conclusions}

From the experimental study discussed here, it may be concluded that TODGA is the best solvent among all the four solvents viz., TBP, D2EHPA, MIBK and TODGA for the extraction of nitric acid from effluents containing free nitric acid. The distribution coefficient of nitric acid in TODGA is higher than that in TBP. Similarly, the distribution coefficient of nitric acid in TBP is higher than that in MIBK and same in MIBK is higher than that in D2EHPA. From the experiments on stripping of the extracted nitric acid, it was found that almost quantitative stripping of nitric acid is possible in case of all the four solvents.

It may be noted that TBP is the cheapest and TODGA is the costliest among all the four solvents discussed in this paper. However, cost is not very important in the case of recovery of nitric acid by extraction, because the same solvent can be reused, though some losses will be there due to the solubility of solvent in water. The initial investment due to the cost of solvent may vary depending on the scale of production.

Other solvents better than TODGA may be available. Further screening of various solvents; Suitable for the extraction of nitric acid from aqueous solution or acidic effluent containing free nitric acid may be studied by using molecular modelling to save time.

\section{Acknowledgements}

The author is thankful to thank Md. Nifan, Nuclear Fuel Corporation, Hyderabad who had participated in the experimental studies discussed in this paper. The author is also thankful all the staffs of the Laboratory Services Section of Chemical Engineering Division, Bhabha Atomic Research Centre, Mumbai for carrying out analysis of different samples for the present experimental study.

\section{References}

1. Mirvish S (1985) Gastric cancer and salivary nitrate and nitrite. Nature 315: 461-462.

2. Canter LW (1996) Nitrate in groundwater. CRC Press, Boka Raton, USA.

3. Milmile SN, Pande JV, Karmakar S, Bansiwal A, Chakrabarti T, et al. (2011) Equilibrium isotherm and kinetic modeling of the adsorption of nitrates by anion exchange Indian NSSR resin. Desalination 276: 38-44.

4. Weisen burger DD (1993) Human health-effects of agrichemical use. Human Pathology 24: 571-576.

5. Azizullah A, Khattak MNK, Richter P, Häder DP (2011) Water pollution in pakistan and its impact on public health - a review. Environment International 37: 479-497.

6. Ward MH, Brender JD (2011) Drinking water, nitrate and health. Encyclopedia of Environmental Health 3: 67-178.

7. Camargo JA, Alonso A (2006) Ecological and toxicological effects of inorganic nitrogen pollution in aquatic ecosystems: A global assessment. Environ Int 32: 831-849.

8. Liang S, Mann MA, Guter GA, Kim PHS, Hardan DL (1999) Nitrate removal from contaminated groundwater. Journal of American Water Works Association 91: 79-81.

9. Mandal D (2003) Denitration of liquid waste. Indian Chemical Engineer 45: 203-206.

10. Inamori Y, Takai T, Sudo R (1993) Recent aspects of nitrogen and phosphorus removal technology. Sigen Kankyo Taisaku 29: 728-739.

11. Mattus AJ, Lee DD, Dilloe TA, Farr LL, Loghry SL, et al. (1994) Low-temperature process for the denitration of Hanforrd Single-Shell tank, nitrate-based waste utilizing the nitrate to ammonia and ceramic (NAC) process. ORNL/TM-12245, Contract DEAC05840R21400, Oak Ridge National Laboratory, Oak Ridge, USA.

12.Jaiswal SK, Mandal D, Visweswara Rao RVRL (2015) Recovery and reuse of nitric acid from effluents containing free nitric acid in absence and presence of metal nitrates. Chemical Engineering Journal 266: 271-278. 
13.Kapoor A, Viraraghavan T (2015) Nitrate removal from drinking water-review. Journal of Environmental Engineering 123: 371-380.

14.Biswas S, Pathak PN, Singh DK, Roy SB, Manchanda VK (2012) Evaluation of dinonyl phenyl phosphoric acid (DNPPA) and its synergistic mixtures with neutral-oxodonors for extraction and recovery of uranium from nitric acid medium. Int J Min Proc 104-105: 17-23.

15.Shin CH, Kim JY, Kim JY, Kim HS, Lee HS, et al. (2009) Recovery of nitric acid from waste etching solution using solvent extraction. J Hazardous Mat 163: 729734.

16.Lee MS, Ahn JG, Ahn JW (2003) Recovery of copper, tin and lead from the spent nitric etching solutions of printed circuit board and regeneration of the etching solution. Hydrometallurgy 70: 23-29.

17.Xianghong, Zhou $L$ (1996) Extraction kinetics of nitric acid by TBP. J Chem Eng Chinese U 2: 8-12.

18.Usachev VN, Markov GS (2003) Incidents caused by red oil phenomena at semi-scale and industrial radiochemical units. Radiochemistry 45: 1-8.

19.Sato Y, Murayama K, Nakap T, Takahashi N (1995) Nitric acid adsorption by a phosphonic acid ester type adsorbent. Wat Res 29: 1267-1271.

20.Kulkarni PS (2003) Recovery of uranium (VI) from acidic wastes using tri-n-octyl-phosphine oxide and sodium carbonate based liquid membranes. Chem Eng J 92: 209-214.

21.Stankovic V, Outarra L, Zonnevijlle F, Comninellis Ch (2008) Solvent extraction of silver from nitric acid solutions by calyx arene amide derivatives. Separation and Purification Technology 61: 366-374.

22.Alcock K, Grimley SS, Healy TV, Kennedy J, Mckay HAC (1956) The Extraction of nitrates by tri-n-butyl phosphate (TBP) Part I-The System TBP + Diluent + H2O +HNO3. Trans Faraday Soc 52: 39-47.

23. Mishra S, Ganesh S, Velavendan P, Pandey NK, Mallika C, et al. (2013) Thermodynamics of solubility of tri-n-butyl phosphate in nitric acid solutions. Advanced Chemical Engineering Research 2: 55-60.

24. Shin CH, Kim JY, Kim JY, Kim HS, Lee HS, et al. (2009) A solvent extraction approach to recover acetic acid from mixed waste acids produced during semiconductor wafer process. J Hazard Mater 162: 12781284.

25.Lan S, Wen X, Zhu Z, Shao F, Zhu C (2011) Recycling of spent nitric acid solution from electro-dialysis by diffusion dialysis. Desalination 278: 227-230.

26.Yu Zhang and Mamoun M (1988) Removal of nitric acid from concentrated phosphoric acid by extraction with methyl isobutyl ketone in aromatic diluents. Solvent Extraction and Ion Exchange 6: 9931006.

27. Fiona Mc Lachlan, Katie G, Andreas G, Bliss ML, Giuseppe $M$, et al. (2016) Nitric acid extraction into the TODGA/TBP solvent. Solvent Extraction and Ion Exchange 34: 334-346.

28. Hesford E, McKay HAC (1958) The extraction of nitrates by tri-n-butyl phosphate (TBP) Part 3-extraction at trace concentrations. Trans Faraday Soc 54: 573-586.

29. Muhammad AM, Sadia I, Humma AC, Shafaq M, Numra S (2017) Recovery of nitric acid from effluent streams using solvent extraction with TBP: A comparative study in absence and presence of metal nitrates. Separation and Purification Technology 186: 90-95.

30. Klamt A (1995) Conductor-like screening model for real solvents: A new approach to the quantitative calculation of solvation phenomena. J Phys Chem 99: 2224-2235. 